\title{
Psychosexual Care and Role of Couples, Interventions on Psychosexual Concerns
}

However, others look at couples impact on erectile function. This was found to be beneficial, as opposed to single patient therapy [1]. The study findings were reconfirmed by [2]. This can be built on with the pathway, and make sure couples are included. Muller-Mattheis et al. [3] conducted teaching for medical students on erectile function and found again, that an interdisciplinary approach is required. The study is limited in that, it uses medical students who have not undergone any procedures, but the principle remains the same.

\section{References}

1. Wittmann D, Carolan M, Given B, Skolarus TA, An L, Palapattu G, Montie JE. Exploring the role of the partner in couples' sexual recovery after surgery for prostate cancer. Support Care Cancer. 2014;22:2509-15.

2. Naccarato A, Reis L, Mendonca G, Denardi F. Post radical prostatectomy erectile dysfunction rehabilitation is couple dependent: a missing piece in the puzzle. Urology. 2013;1:S184.

3. Muller-Mattheis V, Schulz C, Schmelzer R, Mortsiefer A, Rotthoff T, Albers P, Karger A. Evaluation of a new course on teaching of erectile dysfunction following pelvic surgery in men with prostate or bladder cancer in undergraduate medical education. J Cancer Res Clin Oncol. 2012;138:124. 